\title{
O recenseamento escolar de 1920 na imprensa paulista: uma campanha cívica de combate ao analfabetismo ${ }^{1}$
}

Louisa Campbell Mathieson²

\section{Resumo}

A primeira medida tomada por Sampaio Doria quando assumiu a Direção Geral de Instrução Pública de São Paulo, em 1920, foi promover o recenseamento escolar das crianças entre 6 e 12 anos, com o objetivo de saber quantas crianças eram analfabetas, onde elas moravam e quais as condições da região em que moravam. Tomando o recenseamento escolar de 1920 como objeto, este artigo tem como objetivo analisar o papel que a imprensa paulista desempenhou ao promover uma campanha cívica do recenseamento, interferindo na produção do fato. Analisa-se o modo como a imprensa divulgou o recenseamento entre junho e setembro, entendendo-a como sujeito da história, que agenda, seleciona, registra e comenta assuntos da esfera pública. Tem-se a hipótese de que o efeito social promovido pela cobertura da imprensa auxiliou a alavancar a Reforma de 1920, ao agendar o analfabetismo e inflar sua visibilidade. Constituem o corpus documental deste artigo publicações nos jornais Correio Paulistano, O Estado de S. Paulo e Jornal do Commercio. Para análise dos documentos, utiliza-se como referencial teórico-metodológico a teoria do agendamento, segundo a qual o efeito mais decisivo que os meios de comunicação geram no debate é a própria pauta. Conclui-se que a divulgação do recenseamento escolar pela imprensa amplificou a denúncia do analfabetismo. Ao acompanhar a ação governamental do recenseamento escolar, a imprensa agendou o tema do analfabetismo, alardeando-o com imagens, em concordância com as atividades executadas pelo governo.

\section{Palavras-chave}

Recenseamento escolar - Reforma de 1920 - Sampaio Doria - Imprensa paulista.

1- Artigo derivado da tese de doutorado Vozes impressas: a Reforma de 1920 em pauta na imprensa paulista, financiada pela Coordenação de Aperfeiçoamento de Pessoal de Nível Superior (CAPES).

2- Universidade de São Paulo, São Paulo, SP, Brasil. Contato: Iouisacmathieson@gmail.com 


\section{The 1920 school census in the Sao Paulo press: a civic campaign to combat illiteracy ${ }^{3}$}

\section{Abstract}

When Sampaio Doria became the General Director of Public Instruction of the State of Sao Paulo in 1920, his first measure him was to conduct a school census of children between 6 and 12 years old, in order to know how many children were illiterate, where they lived and what were the conditions of the region in which they lived. Taking the 1920 school census as an object, this article aims to analyze the role played by the Sao Paulo press in promoting a civic campaign for census, interfering with the making of the fact. We analyze how the press publicized the census from June through September, taking the press as an agent of history, as they put matters of the public sphere in the agenda, select them, record them and comment on them. Our hypothesis is that the social effect resulting from the press coverage helped impel the 1920 Reform by drawing attention to illiteracy and inflating its visibility. The sources of this article consist of publications in the newspapers Correio Paulistano, 0 Estado de S. Paulo and Jornal do Commercio. The agenda-setting theory is used as a theoretical-methodological framework, according to which the most decisive effect that the media generates in the debate is the agenda itself. We conclude that the dissemination of the school census by the press amplified the denunciation of illiteracy. By following up the governmental actions regarding the school census, the press set the theme of illiteracy, showing it off with images, in accordance with the activities carried out by the government.

\section{Keywords}

School Census - 1920 Reform-Sampaio Doria - Sao Paulo Press.

Antonio de Sampaio Doria, ao assumir a Direção Geral da Instrução Pública de São Paulo, em 1920, buscou solucionar duas questões centrais: a alfabetização do povo e a nacionalização dos imigrantes. Para cumprir esses objetivos, como primeira ação de sua gestão o diretor sugeriu uma verificação censitária das crianças entre 6 e 12 anos, para que se pudesse obter um mapa considerado imparcial e rigoroso da instrução primária paulista. 0 analfabetismo era entendido como enfermidade, sendo necessário ter um diagnóstico exato para prescrever seu receituário e antídoto.

Sampaio Doria (1923, p. 16) defendia que o analfabetismo era "o monstro canceroso, que hoje desviriliza o Brasil, é a ignorância crassa do povo, o analfabetismo que reina

3- Article resulting from the doctoral dissertation Imprinted voices: the 1920 Reform on the agenda of the Sao Paulo press, funded by Coordination for the Improvement of Higher-Education Personnel (CAPES). 
do norte ao sul do país, esterilizando a vitalidade nativa e poderosa da sua raça”. Em consonância com as concepções higienista, sanitarista e eugênica vigentes no período, essa noção de combate ao analfabetismo, associada à de extirpação de uma doença, também foi amplamente defendida e divulgada pela imprensa.

Tomando o recenseamento escolar de 1920 como recorte, este artigo tem como objetivo analisar o papel que a imprensa desempenhou em sua campanha, interferindo na produção do fato, ao noticiá-lo cotidianamente ao longo de junho a setembro respectivamente, início da organização do recenseamento e divulgação dos dados recenseados. Percorremos o modo como a imprensa divulgou as ações do recenseamento, enfocando as representações e os usos de números estatísticos.

Trata-se, portanto, de tomar a imprensa como sujeito da história, que agenda, seleciona, registra e comenta assuntos da esfera pública. Cotejamos os mecanismos de produção dos números e o debate mais circunscrito à estatística educacional, com a hipótese de que o efeito social promovido pela cobertura da imprensa auxiliou a alavancar a reforma, ao agendar o analfabetismo e inflar sua visibilidade. Interessam-nos, assim, mais os discursos veiculados, os usos dos dados pela imprensa e suas representações sobre o recenseamento do que a análise dos números.

Constituem o corpus documental deste artigo diferentes tipos de publicações na divulgação do recenseamento, como artigos, cartas, editoriais, infográficos, tabelas, circulares, todos publicados nos jornais Correio Paulistano, O Estado de S. Paulo e Jornal do Commercio. Para a análise dos jornais, utiliza-se a teoria do agendamento, a qual trabalha com a ideia de que o efeito mais decisivo que os meios de comunicação geram no debate é a própria pauta (HOHLFELDT, 1997). Como fonte auxiliar, o relatório de Recenseamento escolar (DORIA, 1920) foi usado para a compreensão da organização do censo. Trata-se de documento oficial que foi escrito e entregue por Sampaio Doria a Alarico Silveira, secretário dos Negócios do Interior, pasta que geria a Instrução Pública.

Sobre a produção de estatísticas educacionais, Gil (2007, p. 17) analisa a:

[...] legitimidade que usufruem as estatísticas educacionais para a condução de decisões políticas e de que maneira estas colaboram na formulação de representações sobre a escola primária brasileira.

De modo análogo, vemos o recenseamento escolar de 1920, ancorado no aparato do Estado, criando imagens sobre a escola primária paulista a partir de "informações numéricas consideradas confiáveis" (GIL, 2007, p. 17).

Senra (2006, p. 31) deixa claro que os Estados buscam "enumerar, mensurar e quantificar suas populações”, fornecendo aos governos subsídios para ancorar as políticas públicas que almejam implantar. Isso porque os dados censitários, tidos como racionais e objetivos, imprimem certo retrato social. Besson (1995) mostra que há uma expectativa de que os dados sejam exatos, embora, como o próprio autor pondera, isso seja impossível, pois não se trata de uma fotografia, mas de uma observação sempre relativa e modelizada da realidade. Os dados estatísticos são da ordem do operatório, pois "toda observação estatística é afetada por um certo grau de inexatidão” (BESSON, 1995, p. 29), tanto maior 
se o objeto de análise for um censo, tal qual o recenseamento em tela, que pretendeu observar as crianças entre 6 e 12 anos de todo um estado.

A categorização é estruturante para o fazer da estatística, que lida com um cabedal de informações e busca conferir inteligibilidade aos dados. Sem uma classificação prévia, não há como contar. Souza (2005, p. 205) defende que, uma vez "transformada em aluno", a criança torna-se objeto de um "cálculo contábil" com o respaldo de categorias como aluno, aluna, analfabeto, alfabetizado, normais, anormais, matriculados, não matriculados, meninos, meninas, idade etc., categorias que passam a representar um perfil de escola. As categorias tornam, como apontam Popkewitz e Lindblad (2001, p, 111), "o mundo inteligível e calculável para intervenções políticas e sociais”.

As estatísticas são uma forma de representação de uma sociedade dinâmica, com nuanças e matizes, promovendo simultaneamente uma leitura inteligível do mundo por um espectro, mas também mediante fixação de padrões ao estagnar as pessoas em categorias. As estatísticas não apreendem o todo, mas cumprem o papel de ordenar e sintetizar informações de acordo com uma leitura categorizada do social.

\section{A elaboração do recenseamento escolar e as formas de apoio}

0 recenseamento escolar foi arquitetado em um cenário de apelo patriótico. Para Sampaio Doria, não bastava saber o número de crianças analfabetas, tal como os anuários de ensino vinham registrando, seria também necessário saber onde se encontravam, para traçar um mapa a partir do qual seriam criadas novas escolas. Na ausência de um órgão dentro da Secretaria dos Negócios do Interior para os recensear, os dados educacionais foram coletados por recenseadores que estavam, em sua maioria, na condição de gratuitos: na capital foram 179 e, no interior, 1.345.

Pelo que se verifica dos comunicados na imprensa e pelo relatório de Recenseamento escolar (DORIA, 1920) sobre a participação de voluntários, havia membros e simpatizantes da Liga Nacionalista e escoteiros, além de professores, estudantes e funcionários das câmaras municipais. Os chefes dos municípios estavam incumbidos de instruir e distribuir os recenseadores pelos bairros, bem como deles receber os mapas com os dados coletados, os quais seriam enviados ao chefe de zona, que compilaria os dados e enviaria ao escritório central.

Para os municípios, entendidos como zona urbana, havia um modelo de quadro diferente do designado para a zona rural. 0 recenseador deveria preencher nove colunas, além do campo de observações, com os seguintes dados: 1) nome (só o primeiro); 2) nome do pai ou tutor; 3) residência; 4) profissão do pai ou tutor; 5) idade (6 a 12 anos); 6) sexo; 7) sabe ler?; 8) frequenta escola?; e 9) nacionalidade do pai. 0 balanço total dos dados era preenchido ao final da página, separado conforme o sexo.

0 quadro referente à zona rural continha as mesmas colunas, exceto o tópico sobre a residência, pois o recenseador o preencheria com o nome do distrito ou bairro e o nome da fazenda. A coluna referente às observações deveria ser preenchida com os dados sobre a distância da localidade mais próxima, o mês do plantio e da colheita, se alguém 
facilitaria a localização da escola, qual seria o lugar preferível para a escola, se o professor poderia residir no bairro. É possível inferir a partir do instrumento de coleta que uma das causas do analfabetismo e da baixa frequência escolar no campo, além da carência de escolas e professores, era o trabalho das crianças na roça.

No relatório do Recenseamento escolar (DORIA, 1920) não há um detalhamento sobre a construção dos dados, dos critérios eleitos ou, ainda, dos dados complementares da população recenseada, isto é, não encontramos uma elucidação metodológica de como o censo foi realizado. Problematizar a estruturação de uma pesquisa quantitativa faz-se uma operação necessária, pois as perguntas e categorias eleitas para o questionário censitário - que com frequência são confundidas com retratos fiéis do fenômeno que registram - determinam a descrição que será feita. Ao apresentarem as categorias recenseadas, os quadros de registro compõem o instrumento metodológico que encontramos sobre o recenseamento escolar. A partir delas, inferimos uma concepção de escola preocupada com a capacidade de as crianças saberem ler ou não, pois o censo não questionava outros aspectos da dimensão escolar nem questionava outros agentes escolares.

0 recenseamento escolar foi fartamente debatido no Correio Paulistano, n'O Estado de S. Paulo e no Jornal do Commercio entre junho e setembro de 1920, em que destacamos o que denominamos formas de apoio que o recenseamento escolar solicitou e recebeu de diferentes instituições, sendo a própria publicação e divulgação do censo uma clara manifestação de que esses jornais apoiaram a medida governamental em curso.

A divulgação do recenseamento escolar na imprensa teve início em 18 de junho de 1920, quando foi dada a ordem para sua execução. Nesse dia, o Correio Paulistano e $O$ Estado de S. Paulo publicaram a mesma notícia acerca da "campanha de desanalfabetização da população". O texto é emblemático, pois anuncia o tom pelo qual o tema do recenseamento seria abordado nos dias e semanas seguintes nos jornais analisados. Foi anunciado também ser indispensável saber quantos eram os analfabetos, onde se encontravam e em que condições viviam. Essas três questões reapareceriam constantemente nas publicações do período, constituindo o eixo central da campanha contra o analfabetismo.

Ressaltamos que o dia de publicação dessas notícias é o mesmo da publicação da ordem de execução do recenseamento e no dia seguinte houve a abertura do escritório central do recenseamento na Escola Normal da Praça. Assim, havia uma enorme movimentação para a boa realização do censo que se iniciava. Em tom favorável, o texto dava visibilidade às ações do governo em relação ao censo, cujo tempo de realização era limitado, pois precisaria ser finalizado até setembro, devendo a campanha contra o analfabetismo ter início imediato.

Sendo esse um serviço, por sua natureza, dispendiosíssimo, o Estado tem de apelar, para a sua realização imediata, para a boa vontade de quantos se encontrarem em condições de o auxiliar de qualquer forma, muito esperando, nesse sentido, dos sentimentos cívicos do clero paulista, dos estudantes dos cursos superiores e que se encontram no interior, em férias, dos professores e professoras, os quais todos podem, fazendo entre o povo a propaganda do recenseamento escolar, esclarecer as populações, sobretudo as rurais, acerca dos verdadeiros intuitos com que se 
procede a este serviço, mostrando-lhe a sua absoluta necessidade como meio único de lhes serem fornecidas as escolas de que necessitam. (NOTAS, 1920, p. 1; A LUTA..., 1920, p. 4).

A todo momento a Diretoria Geral da Instrução Pública solicitava ampla colaboração das pessoas na execução do censo e em sua divulgação à população para dirimir dúvidas sobre a tarefa em curso. O Jornal do Commercio noticiou que quase todas as câmaras municipais do estado estavam "inteligentemente" interessadas pelo recenseamento escolar e estavam manifestando valiosos oferecimentos, com voluntários, estada, materiais e despesas, facilitando, assim, os trabalhos. Os sentimentos de patriotismo e civismo permearam o tom do discurso, como um chamado para o cumprimento de um dever cívico.

Carvalho (1990) mostra que, em momentos de mudança ou fragilidade política, a disputa pelo imaginário é travada com o intuito de definir identidades, objetivos e inimigos por meio de símbolos, alegorias, rituais e mitos. Com a eclosão da Primeira Guerra Mundial, pensar uma identidade nacional tornou-se palavra de ordem e possibilidade renovada de pensar as questões nacionais. Pensando especificamente o projeto nacionalista paulista dos anos de 1910 e $1920^{4}$, percebemos, quando da defesa de questões cívicas - como a modernização do país, a alfabetização da população, a organização do trabalho -, um projeto pautado em um discurso nacionalista atravessado pelo autoritarismo, seja pelo controle social, seja por prescrever o que seria melhor para o outro. A elite ilustrada buscava efetivar um projeto social e forjar uma identidade nacional em nome da regeneração da pátria, mas pela reforma dos costumes e pela formação de um tipo ideal de cidadão, trabalhador e educado moral e civicamente, sem colocar em xeque a hegemonia paulista.

Também em 18 de junho, o Jornal do Commercio publicou uma breve nota informando que Alarico Silveira aprovara a continuidade do recenseamento. Observa-se que essa tribuna não publicou a mesma notícia publicada no Correio Paulistano e n'O Estado de S. Paulo. Como órgão oficial do governo, o Correio Paulistano defendia em suas pautas a manutenção e a situação do Partido Republicano Paulista (PRP). Pela ampla cobertura dos atos oficiais e expedientes burocráticos do governo, condizia com o tom geral desse matutino a publicação de uma nota possivelmente preparada pelo governo, defendendo a ação do recenseamento escolar.

Por sua vez, O Estado de S. Paulo colocava-se como um jornal independente e crítico ao PRP, visto que Julio de Mesquita pertencia à ala dissidente. Dentre os colaboradores desse matutino, entusiasta da temática da instrução, não por acaso nele encontramos vários membros da Liga Nacionalista. Assim, entendemos que a defesa da reforma por esse matutino deve-se ao pertencimento de Sampaio Doria à Liga Nacionalista, e não à simples defesa de uma medida governamental, tal qual fazia o Correio Paulistano.

No mesmo dia, foi publicada no Correio Paulistano - e no dia seguinte n' O Estado de S. Paulo - uma nota informando que Sampaio Doria enviara a todas as comissões regionais de escoteiros uma circular em que, pedindo ajuda à Associação Brasileira de Escoteiros, convocava seus membros a auxiliar na execução do recenseamento, afirmando que eles não poderiam deixar de cooperar com uma campanha oficial de elevada importância

4- Isso sem querermos tratar São Paulo como único estado do Brasil, ou ainda como um projeto hegemônico de nação e de escola, mas em todo caso atentando também para isso, tendo em vista que a elite ilustrada paulista buscava alavancar a suposta superioridade de São Paulo. 
cívica e patriótica. A Associação Brasileira de Escoteiros, da qual Sampaio Doria era membro, compunha o conjunto de redes de relações que foi acionado com a finalidade de auxiliar os serviços do censo para sua efetivação e sucesso.

Para a realização exitosa do recenseamento escolar, a Diretoria Geral da Instrução Pública serviu-se de diferentes sujeitos e entidades para divulgar a campanha contra o analfabetismo. Uma das ações foi enviar uma circular, assinada pelo professor Sud Mennucci, aos jornais e publicada em 23 de junho no Correio Paulistano e no Jornal do Commercio, revelando uma vez mais o consórcio da imprensa com o Estado.

Para que esse empreendimento venha a surtir os resultados desejados, faz-se mister que uma propaganda prévia seja iniciada, a fim de estimular as populações no sentido de fazer que elas se tornem o melhor auxiliar dos que forem encarregados da sua realização. Tal propaganda, nenhum outro órgão a praticará com mais proveito do que a imprensa, da qual o jornal por v. exc. dirigido é brilhante e ativa parcela. Solicitamos, pois, a cooperação dos redatores dessa folha no trabalho de facilitar a tarefa do recenseamento escolar. Esperando do alto espírito e do comprovado patriotismo de v. exc. que este pedido merecerá a devida consideração, temos a honra de, em nome do Estado de S. Paulo, agradecer, de antemão, o valioso concurso representado por este serviço. (O RECENSEAMENTO..., 1920, p. 1; RECENSEAMENTO..., 1920a, p. 5).

A circular de Sud Mennucci é um exemplo de destaque da função social da imprensa (CAMPOS, 2012; DARNTON, 1990; CAPELATO, 1988): ao engrandecer os jornais como veículos de exposição e de ampla divulgação, a circular enaltecia em especial a redação à qual foi dirigida. Sampaio Doria, em diferentes momentos, usou da imprensa como meio para difundir e propagandear a campanha contra o analfabetismo a partir do recenseamento escolar. 0 governo recorreu a diversas formas de apoio junto a prefeituras, câmaras, entidades, professores, agentes da sociedade civil e imprensa para que os paulistas soubessem que se tratava de uma iniciativa do governo e de sua importância, pois, caso não respondessem, a racionalidade e a eficiência das estatísticas estariam postas a perder.

0 recenseamento foi projetado como uma campanha de caráter cívico e patriótico, encabeçada pela Diretoria Geral da Instrução Pública, mas ao mesmo tempo encampada pelos jornais, cumprindo sua função de fazer a mediação entre o Estado e a sociedade civil. Paralelamente, os jornais produziram novos significados em torno do censo ao construírem uma pauta sobre o tema, selecionando os aspectos que queriam ver valorizados. Era uma estratégia política de divulgar o analfabetismo como notícia indesejada para, em contrapartida, conseguir adesão para o seu combate.

Como divulgador das ações do governo, em 24 de junho foi publicado no Correio Paulistano o ofício-circular enviado por Alarico Silveira aos prefeitos de todas as municipalidades do estado, buscando colaboração e apoio dos municípios com vistas ao êxito da campanha contra o analfabetismo. Foi recorrente, além disso, o pedido de auxílio às câmaras municipais e prefeituras para o transporte e a hospedagem dos recenseadores, além do custeio das despesas do censo. A verificação buscava um quadro geral das crianças analfabetas no estado e, para isso, era necessário o auxílio dos diversos órgãos, instâncias do governo e setores da sociedade. 
Assim, não seriam apenas os poderes públicos que financiariam o censo em curso, sendo chamadas também associações da sociedade civil a contribuir com custeio e voluntários. Os pedidos de apoio fundamentavam-se, todos, no apelo patriótico. A ideia de patriotismo era inapelável, inquestionável e, por isso mesmo, amiúde usada como recurso nos pedidos da Diretoria Geral da Instrução Pública a diferentes grupos, de prefeitos a escoteiros.

0 Estado de S. Paulo e o Jornal do Commercio publicaram uma propaganda da Liga Nacionalista. Apesar da diagramação diferente, em ambas a propaganda estava diagramada com uma moldura, realçando o anúncio e convidando o leitor à sua leitura:

Figura 1 - Publicação da Liga Nacionalista no Jornal do Commercio.

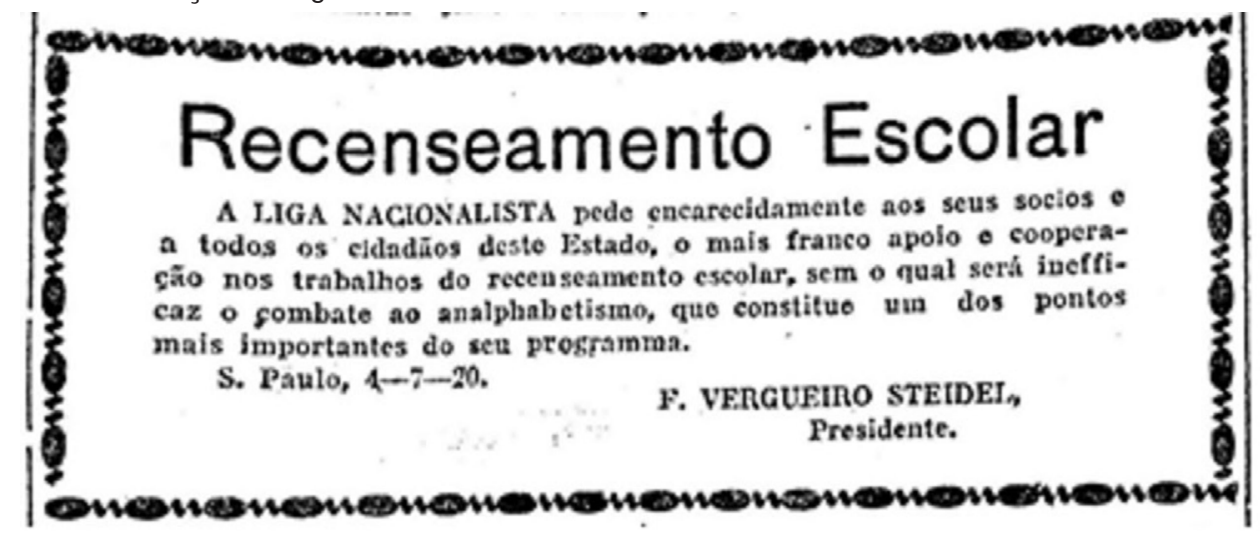

Fonte: (STEIDEL, 1920, p. 2).

Acervo: Hemeroteca do Arquivo Público do Estado de São Paulo.

Uma vez que Sampaio Doria era membro fundador, militante ativo e porta-voz da Liga Nacionalista, ter uma nota da entidade publicada em prol do recenseamento certamente não foi empreitada difícil, ainda que posteriormente tenha havido dissensos na entidade frente à reforma. Como retrata Boto (1990, p. 236), "nessa ocasião, a Liga Nacionalista colabora com a própria execução de seus princípios já que um de seus mais destacados líderes assume em São Paulo a diretoria da instrução pública”.

Sampaio Doria vislumbrava que São Paulo deveria ter o protagonismo de sanar a chaga do analfabetismo, exaltando sua posição de liderança nacional.

[...] São Paulo, resolvendo o problema do analfabetismo, será o núcleo da reação. Tendo a responsabilidade histórica de haver dilatado, com a epopeia dos bandeirantes, as fronteiras do país, e, sendo hoje o maior sustentáculo da riqueza nacional, São Paulo será o supremo guarda das tradições, e o criador supremo do futuro da Pátria. (DORIA, 1920, p. 6).

A "glória paulista" é evocada como um dos discursos mais intensos do período (CAMPOS, 2009). A imagem mítica do bandeirante, representante da grandiosidade colonial paulista, foi retomada por diversos autores nos anos após a proclamação da República. Luca (1999) analisou como a Revista do Brasil atesta em suas páginas um 
renovado interesse pela figura do bandeirante, culminando na década de 1920 com a publicação das obras de Alfredo Ellis Junior, Affonso Taunay, Paulo Prado e Alcantara Machado.

Como examina Abud (1985), com o intuito de retomar uma personagem histórica e construir uma identidade para o povo brasileiro, o bandeirante foi elevado a símbolo nacional e a São Paulo foi atribuído lugar de destaque, por ser o berço dos bandeirantes. Com a República, "São Paulo passava a formar o ponto axial do projeto nacional. Novamente, sua história voltou a se identificar com a do Brasil” (ABUD, 1985, p. 206). 0 bandeirante seria o modelo exemplar que encarnava diferentes virtudes do herói e nele estaria a origem da nação, representando o mito fundador de que o país carecia.

Como Luca (1999) disserta, ele era pioneiro, desbravador, destemido, independente, líder, leal, apagando qualquer traço que pudesse colocar em xeque seu papel heroico, e os paulistas, guardiões legítimos do passado glorioso, seriam os bandeirantes, em uma linha de continuidade direta desde os tempos coloniais.

Em síntese, como relata Abud (1985, p. 138), o bandeirante foi simultaneamente o símbolo da entidade paulista e categoria unificadora que mantinha a integração ao redor de São Paulo, atuando na construção do "patriotismo paulista, associado a um orgulho de linhagem". Silva (2015) defende que a identidade paulista, ao se apoiar na figura do bandeirante, circunscrevia-se em uma identidade racial específica - miscigenada entre brancos e índios - que se colocava, na visão das elites, como expressão do modelo para o povo brasileiro, sem que fosse preciso enfrentar a questão racial dos negros.

Pensando a decorrência da evocação da figura do bandeirante, evidencia-se o papel que São Paulo se atribuía de liderança no plano nacional e a função pedagógica de ser um modelo e um exemplo ao restante do país. Ademais, a associação entre a lógica racional e a lógica de planejamento que perpassam o recenseamento escolar de 1920 estava diretamente relacionada ao mito do herói bandeirante.

Se a figura do bandeirante apagou tudo o que pudesse atrapalhar seu heroísmo, apresentando-se uniforme e unívoca, o recenseamento escolar procedeu de forma semelhante: apresentou-se como ação pioneira e de liderança paulista no combate ao analfabetismo, buscando fixar uma unidade a uma identidade diversificada, aprimorando o povo ignorante, cujo analfabetismo materializava-se em sujeitos que tinham sua cultura marcada pela oralidade e que compartilhavam culturas populares heterogêneas. Nessa perspectiva, combater - seja no âmbito de uma guerra ou de uma doença - o analfabetismo era um empreendimento que buscava o apagamento por completo do diferente, do outro. E à figura do bandeirante cabia o papel de construtor da nacionalidade, mostrando a suposta superioridade paulista, proveniente de grupos específicos com projeção nacional.

Com o início do recenseamento escolar em 15 de julho, o Correio Paulistano publicou uma circular intitulada Recenseamento escolar. Já $O$ Estado de S. Paulo deu mais destaque ao publicar a mesma circular, porém destinada Aos Paulistas, também publicada dessa maneira no relatório de Recenseamento escolar (DORIA, 1920). A moldura ao redor da circular, as letras garrafais do título e o vocativo Aos Paulistas eram um eficaz convite à leitura, com forte carga simbólica ao fazer menção à identidade paulista, encerrando-se com a assinatura da Diretoria Geral da Instrução Pública. 
0 fato de ser uma carta-circular cria uma ainda maior proximidade entre o emissor e o destinatário, tendo em vista que esse gênero textual pressupõe a comunicação interpessoal, no caso entre os paulistas e um órgão do governo. Além disso, ainda que diferentes formatos de cartas estejam presentes na imprensa, esse não é um gênero típico do fazer jornalístico, motivo pelo qual conferia ainda mais destaque à publicação do matutino, em trabalho gráfico que o Correio Paulistano não fez.

Nessa publicação d'O Estado de S. Paulo, é atribuído a São Paulo um lugar de liderança nacional. É dado destaque ao território e às pessoas que nele habitam, em que o estado paulista busca se diferenciar e se distanciar do restante do país. A carta defende que o analfabeto, "pobre criatura, emparedada em rasa ignorância", assemelha-se mais a um "bruto" do que a um "ser de razão", apenas a alfabetização "começa a abrir uma clareira azul para a riqueza sadia, para o progresso moral” (DIRETORIA GERAL... 1920, p. 2).

As ideias de espírito e de natureza humana podem ser lidas, aqui, como a busca por formar uma civilização, em uma chave interpretativa dicotômica: isto é, há um povo humano e um povo não humano, sendo o primeiro civilizado e o segundo primitivo, tese consoante com as que postulavam uma hierarquia entre as raças. Por sua vez, o progresso moral era entendido como uma das características das civilizações mais avançadas, isto é, civilizadas. A carta finalizava da seguinte forma:

Considerai a nobreza do trabalho que vai começar. Se não puderdes cooperar pessoalmente conosco, ao menos acompanhai-nos com a vossa simpatia. Com ela ao nosso lado, no centenário da Independência, raiará claridade em todos os cérebros infantis. Eia, pois, senhores, quando menos por caridade para com as crianças. (DIRETORIA GERAL..., 1920, p. 2).

Em linguagem próxima ao leitor, garantindo que seria dada escola a todas as crianças, a carta solicitava amplo apoio das pessoas, que deveriam colaborar abrindo suas casas para os recenseadores ou ao menos externando simpatia pela nobre causa. 0 final da carta tem caráter exortativo e esperançoso de um futuro promissor e próximo, "no centenário da Independência", valendo-se da metáfora da luz que iluminaria as crianças paulistas. Além disso, a causa social é colocada para os leitores como uma ação de caridade, prática própria da religiosidade católica. A necessidade de divulgação do censo perpassa as páginas dos jornais, corroborando a criação da imagem de um evento cívico e patriótico.

Em síntese, as formas de apoio deixam entrever a diligência da equipe do recenseamento escolar para propagandear o censo. Há uma divulgação entusiasmada sobre o censo com vistas ao combate ao analfabetismo: $O$ Estado de S. Paulo e o Jornal do Commercio, e não só o Correio Paulistano, acompanhavam de perto as ações do governo, ao mesmo tempo que este agia para estar presente cotidianamente nos jornais. Nesse particular, a imprensa comportou-se dominantemente como agente de sustentação das metas governamentais, notadamente a extinção do analfabetismo e de propagação e exortação à colaboração.

Em torno de um aparente consenso a respeito tanto da necessidade de mudar o quadro considerado lastimável da instrução paulista quanto da racionalidade implícita 
na medida censitária, as publicações jornalísticas endossam e ratificam sua necessidade e utilidade, construindo uma representação técnica e racional do censo, não trazendo o tom e o conteúdo críticos que utilizarão ao tratar de outras questões envolvendo a reforma.

\section{Divulgação de resultados}

Cumprindo a função de divulgadores dos dados, os três jornais vinham noticiando os eventos do recenseamento escolar e relatando dados parciais e esparsos. No Jornal do Commercio, localizamos apenas a publicação dos dados referentes à capital, e n'O Estado de S. Paulo, somente o resultado final do estado. Ambos usaram como recurso de divulgação tabelas que seguem a mesma disposição gráfica das tabelas do relatório de Recenseamento escolar. 0 Correio Paulistano foi o único que publicou os resultados da capital e do estado, elaborando dois infográficos.

Em 18 de agosto, o Correio Paulistano publicou os resultados do censo na capital. 0 matutino optou por publicar um infográfico, no qual há quatro meninos desenhados e, abaixo deles, as categorias e os resultados.

Figura 2 - Infográfico com o resultado do recenseamento escolar de 1920 da capital no Correio Paulistano.

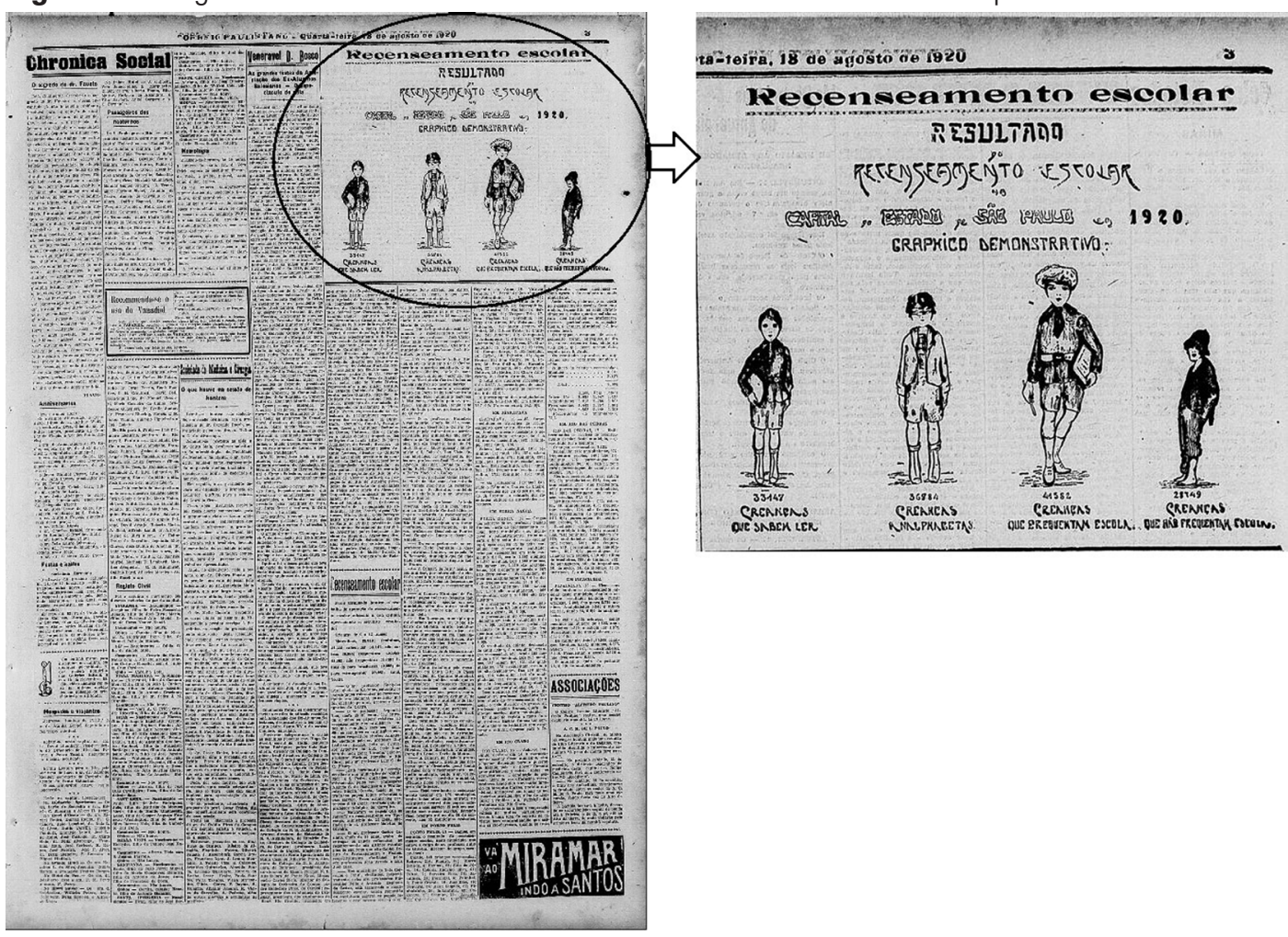

Fonte: (RECENSEAMENTO..., 1920b, p. 3).

Acervo: Hemeroteca da Biblioteca Nacional. Disponível em: <http://bndigital.bn.br/hemeroteca-digital>. Acesso em: 25 abr. 2014 
A mancha gráfica da impressão do infográfico na horizontal quebrava a rotina da massa densa de textos, tradicionalmente dispostos na vertical em colunas estreitas e letras miúdas. Os quatro meninos desenhados representam o quantum indicado pelo número apresentado imediatamente abaixo de cada um deles. Quanto maior o número de crianças recenseadas, maior era o tamanho da criança representada no infográfico.

0 primeiro menino da esquerda para a direita pertencente à categoria de "crianças que sabem ler", está com o cabelo penteado, bem trajado e carrega um caderno ao lado do corpo, representação análoga à do terceiro menino, que pertence à categoria de "crianças que frequentam a escola" e que corresponde ao maior número das quatro categorias, trazendo um chapéu vistoso, gravata, sapatos e carregando um caderno na mão esquerda e uma caneta na mão direita. 0 segundo menino, que representa o número de analfabetos, tem seus olhos vendados e não carrega objetos. 0 quarto menino, que representa o menor valor, está descalço, com roupas esfarrapadas e um chapéu que encobre o rosto, tendo uma postura de lado e o corpo encurvado, representando a categoria de "crianças que não frequentam escola”. As imagens constituem um texto não verbal que cria associações que, postas em movimento, agregam representações ao discurso verbal.

A venda nos olhos das crianças analfabetas não caracterizaria, contrario sensu, a representação do saber como "luz" e "iluminação"? E que dizer quanto à associação entre ser alfabetizado e ter boas roupas e postura ereta? Há uma imagem do conhecimento como luz e da ignorância como escuridão. 0 movimento iluminista ou o Século das Luzes é a expressão máxima da ideia de razão como luz. Portanto, registrar ao lado de dados estatísticos imagens que simbolizariam interpretações de mundo é uma forma de conduzir o leitor por meio de um discurso imagético e, no limite, ensinar como deve ser lido o cenário social que está sendo apresentado pelos números.

Luca (2005, p. 140) afirma que:

[...] os discursos adquirem significados de muitas formas, inclusive pelos procedimentos tipográficos e de ilustração que os cercam. A ênfase em certos temas, a linguagem e a natureza do conteúdo tampouco se dissociam do público que o jornal ou revista pretende atingir.

Nesse diapasão, Campos (2012, p. 63) chama a atenção para o fato de que "esse universo comum é o que verdadeiramente caracteriza a força educativa dos impressos: uma espécie de contrato invisível entre os que leem e os que escrevem nos jornais”. Isto é, para evitar quaisquer dúvidas do que representa ser analfabeto ou saber ler, o jornal, em uma função pedagógica, direcionava a interpretação do significado social desses números.

Assim, permanecer fora da escola corresponderia a um retrato social de um rosto encoberto, roupas rotas e postura arqueada, naturalizando um retrato simbólico. Entendemos que, para o jornal, tirar as vendas dos analfabetos seria uma empresa mais facilmente realizável do que alterar o comportamento, a postura e o vestuário de crianças que não frequentavam a escola, haja vista o modo como foram desenhados o segundo e o quarto meninos da esquerda para a direita. Chama-nos a atenção o fato de crianças, cuja condição mesma é condizente com não saber ler, serem desde cedo estigmatizadas.

Noticiando a mesma informação publicada no Correio Paulistano sobre o resultado do recenseamento na capital paulista, o Jornal do Commercio, em 22 de agosto, divulgou uma 
tabela com 11 colunas, com as categorias; e nove linhas, a primeira delas composta pelas categorias referidas, seguida das idades de 6 a 12 anos e, ao final, do somatório total das idades.

Figura 3 - Resultado do recenseamento escolar de 1920 da capital publicado no Jornal do Commercio.

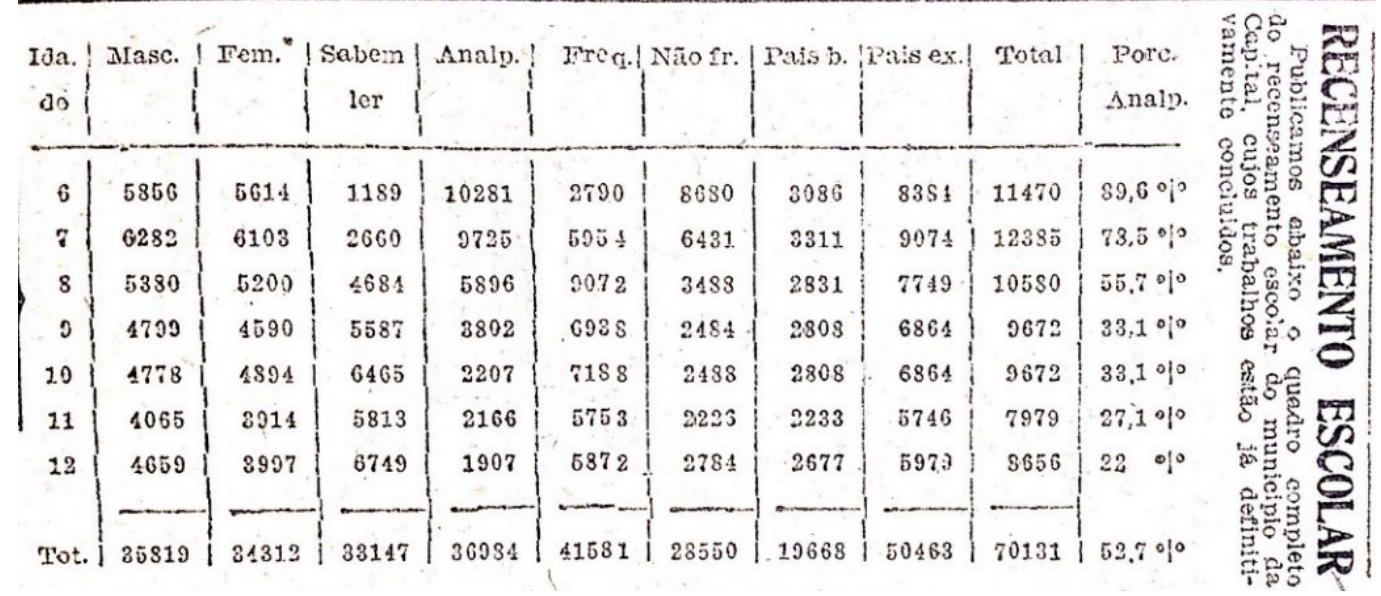

Fonte: (RECENSEAMENTO..., 1920c, p. 5).

Acervo: Hemeroteca do Arquivo Público do Estado de São Paulo.

Os resultados apresentados até aqui dizem respeito especificamente à capital paulista - um espaço urbano em que a maioria das crianças frequentava a escola e no qual, em comparação com o restante do estado, havia uma considerável rede de escolas. De acordo com os dados divulgados no Jornal do Commercio, o número de crianças com pais estrangeiros é expressivo, por volta de 70\%, dado não divulgado pelo Correio Paulistano. As categorias do recenseamento conformam uma maneira de representar as crianças e a própria instrução pública, coadunando-se com as metas de Sampaio Doria de erradicação do analfabetismo e nacionalização do ensino primário. Paralelamente ao combate ao analfabetismo, a nacionalização do ensino era outro alicerce da reforma. Como membro da Liga Nacionalista, Sampaio Doria defendia a regeneração da pátria brasileira, elevando o povo ao estatuto de cidadão, por meio da alfabetização, nacionalização, instrução moral e cívica.

Analisamos uma mesma notícia sendo veiculada de duas maneiras diferentes, que expressam intencionalidades: enquanto o Correio Paulistano publicou um infográfico com o resultado de apenas quatro categorias, o Jornal do Commercio publicou uma tabela com os resultados de todas as categorias recenseadas por idade. A representação utilizada pelo Correio Paulistano, embora convidativa para o leitor, não trazia diversas categorias nem registrava os resultados por idade. Contudo, apresentava uma riqueza de detalhes sobre o perfil de cidadão que se almejava forjar, pois, ao desenhar crianças de modos distintos, criava e interpretava a realidade, fazendo com que o leitor tivesse uma percepção do cenário social aferido, mesmo que não em termos estritamente racionais. Portanto, por meio de uma linguagem verbo-visual, somam-se elementos à construção da representação das crianças que frequentavam ou não a escola e que sabiam ou não ler. Ser analfabeto era estar vendado, como alguém incapaz de enxergar; não frequentar a escola era ter as roupas puídas, postura cabisbaixa e pés descalços. 
Dos três jornais analisados, $O$ Estado de $S$. Paulo foi o único a publicar os resultados finais do recenseamento em 7 de setembro de 1920, dia da comemoração da Independência do Brasil, fazendo com que a divulgação fosse entendida como medida patriótica.

Figura 4 - Resultado final do recenseamento escolar de 1920 do estado de São Paulo publicado n'0 Estado de S. Paulo
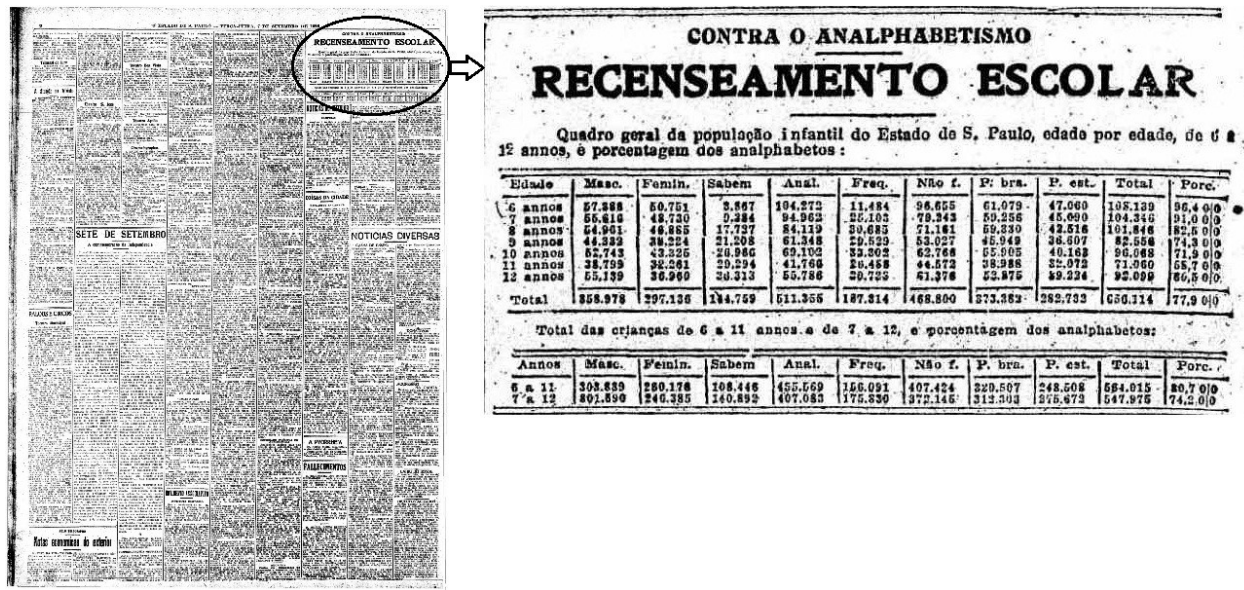

Fonte: (CONTRA..., 1920, p. 4).

Acervo: Acervo Estadão online. Disponível em: <http://www.estadao.com.br/>. Acessado em: 27 mar. 2014.

A tabela publicada n' O Estado de S. Paulo era similar à tabela impressa no relatório de Recenseamento escolar, exceto pelos textos que as acompanham, conforme se observa na figura 5.

Figura 5 - Resultados gerais do recenseamento escolar de 1920.

Os quadros que se seguem, deixam bem claro a situação actual da instrucção primaria no Estado: Eis o resumo geral do recenseamento das crianças entre 6 e 12 annos:

\begin{tabular}{|c|c|c|c|c|c|c|c|c|c|c|}
\hline Edade & Masc. & Femin. & Sabem & Anal. & Freq. & Nāo f. & P. bra. & P. ext. & Total & Porc. \\
\hline 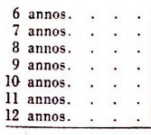 & $\begin{array}{l}57388 \\
55616 \\
54961 \\
43332 \\
52743 \\
38799 \\
55139 \\
\end{array}$ & $\begin{array}{l}50751 \\
48730 \\
46885 \\
38224 \\
43325 \\
32261 \\
36960 \\
\end{array}$ & $\begin{array}{r}3867 \\
9384 \\
17727 \\
21208 \\
26966 \\
29294 \\
36313 \\
\end{array}$ & $\begin{array}{r}104272 \\
94962 \\
84119 \\
61348 \\
69102 \\
41766 \\
55786 \\
\end{array}$ & $\begin{array}{l}11484 \\
25103 \\
30685 \\
29529 \\
33302 \\
26488 \\
30723 \\
\end{array}$ & $\begin{array}{l}96655 \\
79243 \\
71161 \\
53027 \\
62766 \\
44572 \\
61376 \\
\end{array}$ & $\begin{array}{l}61079 \\
59256 \\
59330 \\
45949 \\
55905 \\
38988 \\
52875 \\
\end{array}$ & $\begin{array}{l}47050 \\
45090 \\
42516 \\
3607 \\
40163 \\
32072 \\
39224 \\
\end{array}$ & $\begin{array}{r}108139 \\
104346 \\
101816 \\
82556 \\
96068 \\
71060 \\
92099 \\
\end{array}$ & $\begin{array}{l}96,4 \% \\
91,0 \% \\
82,5 \% \\
74,3 \% \\
71,9 \% \\
58,7 \% \\
60,5 \% \\
\end{array}$ \\
\hline Total . . & 358978 & 297136 & 144759 & 511355 & 187314 & 468800 & 373382 & 282732 & 656114 & $77,9 \%$ \\
\hline
\end{tabular}

Eis a porcentagem de analphabetos entre 7 e 12 annos, e a entre 6 e 11:

\begin{tabular}{|c|c|c|c|c|c|c|c|c|c|c|}
\hline Annos & Masc. & Femin. & Sabem & Anal. & Freq. & Não $f$. & P. bra. & P. ext. & Total & Porcent. \\
\hline $\begin{array}{ccc}6 & \text { a } & 11 \\
7 & \text { a } & 12\end{array}$ & $\begin{array}{l}303839 \\
301590\end{array}$ & $\begin{array}{l}260176 \\
246385\end{array}$ & $\begin{array}{l}103446 \\
140892\end{array}$ & $\begin{array}{l}455569 \\
407083\end{array}$ & $\begin{array}{l}156091 \\
175830\end{array}$ & $\begin{array}{l}407424 \\
372145\end{array}$ & $\begin{array}{l}320507 \\
312303\end{array}$ & $\begin{array}{l}243508 \\
275672\end{array}$ & $\begin{array}{l}564015 \\
547975\end{array}$ & $\begin{array}{l}80.7 \% \\
74.2 \%\end{array}$ \\
\hline
\end{tabular}

Fonte: (DORIA, 1920, p. 87).

Acervo: Biblioteca Central da Escola Politécnica da Universidade de São Paulo. 
0 enunciado da figura 5, escrito provavelmente por Sampaio Doria, evidencia como se acreditava em absoluto nos números. Os quadros "deixam bem claro", apenas com sua leitura, a "situação atual da instrução primária no Estado". De tal modo que verificar o número de crianças que sabem ler/analfabetas e frequentes/não frequentes equivaleria a verificar o estado da instrução primária, como se esta se resumisse a isso. Logo, o efeito da escolarização equivaleria à própria instrução pública e ao juízo que o cidadão pode fazer dela. E a imprensa comunica exatamente esse sentido.

Por sua vez, as letras garrafais e em negrito do título da publicação d'O Estado de $S$. Paulo (figura 4) conferiam destaque à tabela e à campanha de combate ao analfabetismo. Ela estava disposta em 11 colunas, com as mesmas categorias publicadas no Jornal do Commercio sobre o resultado do censo na capital. 0 resultado final do censo escolar de todo o estado paulista revela diferenças em relação aos resultados apresentados sobre a capital: enquanto na capital o número de pais estrangeiros era maior, no estado o número de pais brasileiros era superior.

0 quadro com os resultados finais do estado (figuras 4 e 5) era composto por 11 colunas e nove linhas, a primeira delas contendo as categorias, seguida das idades de 6 a 12 anos e, ao final, o somatório. Em uma segunda tabela, imediatamente abaixo da linha contendo as categorias havia duas outras linhas: uma com o somatório das crianças com idade de 6 a 11 anos, e outra, de 7 a 12 anos. Encontramos apenas no relatório do recenseamento a explicação para essa divisão em dois agrupamentos de crianças: no primeiro grupo, têm-se as crianças que idealmente já estariam na escola (7 a 12 anos); no segundo, as crianças que frequentariam a escola no ano seguinte (6 a 11 anos).

Os dados fornecem uma dimensão qualitativa da pesquisa levada a efeito pelo censo, revelando, ainda que de forma escassa, aspectos atinentes à sua metodologia. Quando $O$ Estado de S. Paulo divulga a mesma tabela, não apresenta, todavia, justificativa para a divisão das crianças em dois grupos, tratando-se de publicação com nuanças imperceptíveis ao leitor leigo ou apressado.

Assim, destacamos que as figuras 3, 4 e 5 permitem entrever um critério metodológico importante do censo, pois exibem os dados parciais divulgados por idade, critério que a figura 2 suprimiu. Entretanto, a própria concepção de idade escolar é arbitrária, sendo uma categorização da infância, ou seja, uma construção social. A justificava de Sampaio Doria para recensear as crianças de 6 anos residia na intenção de obter uma projeção para os próximos anos. Contudo, os dados foram apresentados na imprensa sem a explicação de como fora realizada a sua construção, dando uma impressão aumentada do analfabetismo no estado.

Podemos conjecturar se o censo aferiu todas as crianças na faixa etária ou se não houve erro de contagem, tendo em vista as dificuldades de uma conferência exaustiva. 0 problema, enfim, não reside no resultado, mas no modo como a informação foi divulgada, realçando a amplitude do analfabetismo. Aqui, vemos uma vez mais a imprensa sendo um dos sujeitos que atuam no processo social: nesse caso, estampando claramente em suas páginas o analfabetismo como funesta chaga a grassar pelo estado.

0 ponto fulcral da interpretação do recenseamento escolar de 1920 está em se perceber que a verificação censitária contemplou crianças entre 6 e 12 anos. Essa percepção diz respeito à própria metodologia do censo. Até aqui, apenas as divulgações 
do Jornal do Commercio e d'O Estado de S. Paulo (figuras 3 e 4) deixam entrever - e isso somente com algum esforço interpretativo e conhecimento de cunho pedagógico - esse aspecto metodológico da construção dos dados ao apresentarem os resultados separados por idade. 0 infográfico do Correio Paulistano (figura 2) divulgou apenas o somatório, sem apresentar os dados discriminados por idade, não sendo possível fazer esse cotejamento. Dissemos tratar-se de ponto fulcral porque não se poderia esperar senão o analfabetismo da maior parte das crianças de 6 anos, pois não estava previsto que deveriam frequentar a escola, embora poucas pudessem frequentar jardim de infância ou ter algum tipo de ensino doméstico. Já para as crianças de 7 anos estava previsto na Constituição estadual o ensino obrigatório e gratuito, mas boa parte não frequentava a escola, e mesmo as crianças que o faziam estavam em processo de alfabetização, sendo destarte compreensível o elevado número de analfabetos. Não seria razoável, portanto, ter a expectativa de que crianças de 6 e 7 anos soubessem as primeiras letras. Vemos que o censo as contempla, pensando em projeção futura, mas sem um debate pedagógico sobre a noção de idade escolar, reforçando a imagem estigmatizada da criança analfabeta.

Quase uma semana após a publicação oficial do recenseamento escolar, foi publicado, em 13 de setembro, no Correio Paulistano, o resultado final do recenseamento, com uma representação gráfica semelhante à do dia 18 de agosto, porém ainda maior do que a primeira e com diferenças importantes.

Figura 6 - Infográfico com o resultado final do recenseamento escolar de 1920 publicado no Correio Paulistano.

Fonte: (RESULTAD0..., 1920, p. 2).

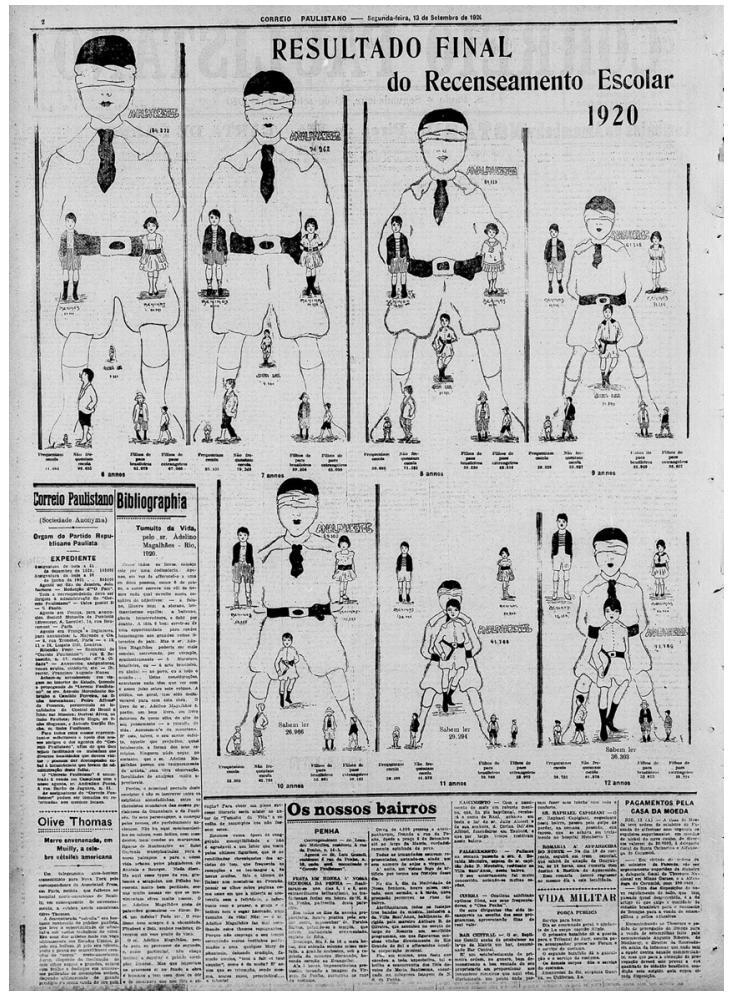

Acervo: Hemeroteca da Biblioteca Nacional. Disponivel em: <http://bndigital.bn.br/hemeroteca-digital>. Acesso em: 23 abr. 2014. 
0 novo infográfico vinha organizado por idade, dos 6 aos 12 anos, e para cada idade havia uma representação que continha oito crianças ilustradas, representando o conjunto total de categorias recenseadas. Além da grandeza do infográfico, que abrangia quase a totalidade da página, observa-se que quanto maior era a ilustração da criança, maior era o número de recenseados.

Pelo fato de o número de analfabetos ser altíssimo, a imagem que sobressaía era a que remetia às crianças com olhos vendados. Uma vez mais, por não conhecerem as primeiras letras, essas crianças não seriam capazes de ver, pois estariam na escuridão. Diferentemente da publicação anterior do Correio Paulistano, composta pelos resultados do censo da capital, nessa publicação as crianças que não frequentavam a escola não foram representadas com roupas rotas, postura retraída, rostos encobertos e pés descalços. As crianças analfabetas, por sua vez, estão representadas de cabelo penteado, usando gravata, cinto, meia, camisa e bermuda. Além das vendas tapando os olhos, as crianças analfabetas têm suas mãos para trás, em contraposição às crianças alfabetizadas, que, além de poderem ver, carregam caderno ao lado do corpo.

Os infográfıcos são imagens verbo-visuais que dizem muito do entendimento da época, haja vista que, quando as palavras parecem ser insuficientes para atribuir sentido ao que se quer comunicar, as imagens são potentes em tocar diretamente os sentidos. Nesse caso, as imagens retratam as próprias crianças carregando o estigma de serem analfabetas, cuja condição não poderia ser senão essa.

Esse cenário mostra-se alarmante e decorre daí a necessidade incontornável de uma campanha sem tréguas de combate ao analfabetismo. E a imprensa, cumprindo seu papel de divulgadora dos dados, inflamou o discurso de um combate militar contra uma epidemia. 0 recenseamento escolar simbolizou uma grande campanha cívica, em que São Paulo, território de ditos grandes feitos, é alçado ao estatuto de liderança do país.

\section{Considerações finais}

Os três jornais analisados não se contrapõem; diferem em suas formas de publicar, mas no mérito convergem com publicações que divulgaram amplamente as atividades do censo. Entendida como um agente social que atua na sociedade civil com a intenção de pautar determinadas notícias em detrimento de outras, a imprensa ocupa e desempenha um papel privilegiado no jogo político, tendo em vista sua forte relação com o Estado. Observamos um duplo movimento: a imprensa acompanhou de perto as atividades do Estado e este, por sua vez, buscou figurar diariamente na imprensa. Outras formas de apoio de que Sampaio Doria se valeu para a divulgação e promoção do recenseamento escolar foram recebidas de instituições da sociedade civil, que buscaram dar credibilidade a ações e iniciativas institucionais da diretoria da Instrução Pública paulista, além de voluntários para a execução do censo.

Consideramos que o recenseamento escolar integra a Reforma de 1920 em seu aspecto técnico, pois era preciso operacionalizar de modo eficaz as diretrizes reformistas mediante um diagnóstico da população escolar e das áreas prioritárias para ação. Em tom dicotômico, ou a criança era alfabetizada ou analfabeta, sem dar margem, por exemplo, para se questionar como foi construída essa situação social, se havia escolas para todos 
ou qual era o lugar social que a escola ocupava em uma sociedade ainda marcadamente rural. 0 recenseamento não buscava coletar informações a respeito da estrutura da escola, dos agentes escolares e das demais etapas do ensino, mas apenas, dada sua arquitetura, informações concernentes ao número de crianças analfabetas, à localização das escolas primárias, à frequência escolar e à nacionalidade.

Ao se desenhar o cenário escolar por meio de números, construía-se uma imagem do estado de São Paulo e uma forma de olhar para esse espaço, concebendo uma ideia de Estado e de povo. Ou seja, ao se organizarem inteligivelmente os dados, organizavamse também as diferenças, homogeneizava-se a dispersão, produzia-se a conformação, fixavam-se padrões, diagnosticavam-se os males, construindo-se, consequentemente, uma imagem de unidade e coesão. Logo, podemos questionar em que medida essa "campanha sem tréguas contra o analfabetismo" acabava sendo um embate em face dos sujeitos analfabetos e sua cultura marcadamente oral. Combater, como em uma guerra, a doença do analfabetismo era uma forma de justificar os modos de vida da cidade e de uma cultura letrada, sem precisar lidar com outros modos de vida. Por outro lado, em uma sociedade em que a cultura letrada passa a ter cada vez mais importância, inclusive pela possibilidade do voto, saber ler e escrever passa a ser uma forma de resistência.

Outrossim, o censo não visa apenas a retratar o cenário social de São Paulo: ele também pretende ensinar qual seria esse cenário. Nesse caso, as imagens apresentadas pelo Correio Paulistano balizam a leitura do retrato social desenhado a partir de categorias, seguidas dos números. Afınal, questões como: o que representa ir para a escola num tempo e espaço em que a maior parte da população é analfabeta e tem como ocupação o trabalho na roça? não são aventadas nos jornais. Portanto, o censo não objetivava apenas identificar, mas irradiar uma proposta de pedagogização da sociedade paulista, ensinando uma determinada visão de mundo, qual seja, a da urgência do combate do analfabetismo no estado de São Paulo.

Demonstrando o amplo analfabetismo da população, o censo funcionou de modo a fornecer sustentáculo à reforma. 0 que o recenseamento escolar - ou, mais precisamente, a sua divulgação pela imprensa - produziu foi a denúncia e a visibilidade do analfabetismo, daí o sensacionalismo ao apresentar os elevados números. Ao cobrir de perto a ação governamental do recenseamento escolar, a imprensa agendou o tema do analfabetismo, alardeando-o e inflacionando-o com imagens, em concordância com as atividades executadas pelo governo. Com o recenseamento escolar, foram apresentados dois problemas e duas saídas possíveis: para o analfabetismo, a campanha de alfabetização; para os estrangeiros, as medidas nacionalistas.

\section{Referências}

A LUTA contra o analphabetismo. 0 Estado de S. Paulo, São Paulo, p. 4, 18 jun. 1920.

ABUD, Katia. 0 sangue intimorato e as nobilíssimas tradições: a construção de um símbolo paulista: 0 Bandeirante. 1985. Tese (Doutorado em História) - Faculdade de Filosofia, Letras e Ciências Humanas da Universidade de São Paulo, São Paulo, 1985. 
BESSON, Jean-Louis. A ilusão das estatísticas. São Paulo: Unesp, 1995.

B0T0, Carlota J. M. C. R. Rascunhos de escola na encruzilhada dos tempos. 1990. Dissertação (Mestrado em Educação) - Faculdade de Educação da Universidade de São Paulo, São Paulo, 1990.

CAMPOS, Raquel Discini de. Mulheres e crianças na imprensa paulista (1920-1940): educação e história. São Paulo: Unesp, 2009.

CAMPOS, Raquel Discini de. No rastro de velhos jornais: considerações sobre a utilização da imprensa não pedagógica para a escrita da história da educação. Revista Brasileira de História da Educação, Maringá, v. 12, n. 1, (28), p. 45-70, jan./abr. 2012.

CARVALHO, José Murilo de. A formação das almas. São Paulo: Companhia das Letras, 1990.

CONTRA o analphabetismo: recenseamento escolar. 0 Estado de S. Paulo, São Paulo, p. 4, 7 set. 1920.

DARNTON, Robert. 0 beijo de Lamourette: mídia, cultura e revolução. São Paulo: Companhia das Letras, 1990.

DIRECTORIA geral da instrucção pública. Aos Paulistas. 0 Estado de S. Paulo, São Paulo, p. 2, 15 jul. 1920.

DORIA, Antonio de Sampaio. Questões de ensino. São Paulo: Monteiro Lobato, 1923.

DORIA, Antonio de Sampaio. Recenseamento escolar. São Paulo: Weizflog Irmãos, 1920.

GlL, Natália. A dimensão da educação nacional: um estudo sócio-histórico sobre as estatísticas oficiais da escola brasileira. 2007. Tese (Doutorado em Educação) - Faculdade de Educação da Universidade de São Paulo, São Paulo, 2007.

HOHLFELDT, Antonio. Os estudos sobre a hipótese de agendamento. Revista FAMECOS, Porto Alegre, v. 4, n. 7, p. 42-51, 1997.

LUCA, Tania Regina de. A Revista do Brasil: um diagnóstico para a (N)ação. São Paulo: Unesp, 1999.

LUCA, Tania Regina de. História dos, nos e por meio dos periódicos. In: PINSKY, Carla Bassanezi (Org.). Fontes históricas. v. 1. São Paulo: Contexto, 2005. p. 111-153.

NOTAS. Correio Paulistano, São Paulo, p. 1, 18 jun. 1920.

O RECENSEAMENTO escolar. Correio Paulistano, São Paulo, p. 1, 23 jun. 1920.

POPKEWITZ, Tom; LINDBLAD, Sverker. Estatísticas educacionais como um sistema de razão: relações entre governo da educação e inclusão e exclusão sociais. Educação \& Sociedade, Campinas, v. 22, n. 75, p. 111-148, ago. 2001.

RECENSEAMENTO escolar. Jornal do Commercio, São Paulo, p. 5, 23 jun. 1920a. 
RECENSEAMENTO escolar. Correio Paulistano, São Paulo, p. 3, 18 ago. 1920b.

RECENSEAMENTO escolar. Jornal do Commercio, São Paulo, p. 5, 22 ago. 1920c.

RESULTAD0 final do recenseamento escolar 1920. Correio Paulistano, São Paulo, p. 2, 13 set. 1920.

SENRA, Nelson. História das estatísticas brasileiras: estatísticas legalizadas (c. 1899 - c. 1936). v. 2. Rio de Janeiro: IBGE: Centro de Documentação e Disseminação da Informação, 2006.

SILVA, Priscila Elisabete da. Um projeto civilizatório e regenerador: análise sobre raça no projeto da Universidade de São Paulo (1900-1940). 2015. Tese (Doutorado em Educação) - Faculdade de Educação da Universidade de São Paulo, São Paulo, 2015.

SOUZA, Cynthia Pereira de. A criança-aluno transformada em números (1890-1960). In: STEPHANOU, Maria; BASTOS, Maria Helena Camara (Org.). História e memórias da educação no Brasil. Petrópolis: Vozes, 2005. p. 195-208.

STEIDEL, Frederico Vergueiro. Recenseamento escolar. Jornal do Commercio, São Paulo, p. 2, 11 jul. 1920.

Recebido em: 23.06.2017

Aprovado em: 25.10.2017

Louisa Campbell Mathieson é doutora e mestra em educação pela Universidade de São Paulo e pedagoga por essa mesma instituição. 